This article was downloaded by: [National Taiwan University]

On: 16 December 2008

Access details: Access Details: [subscription number 788846425]

Publisher Taylor \& Francis

Informa Ltd Registered in England and Wales Registered Number: 1072954 Registered office: Mortimer House, 37-41 Mortimer Street, London W1T 3JH, UK

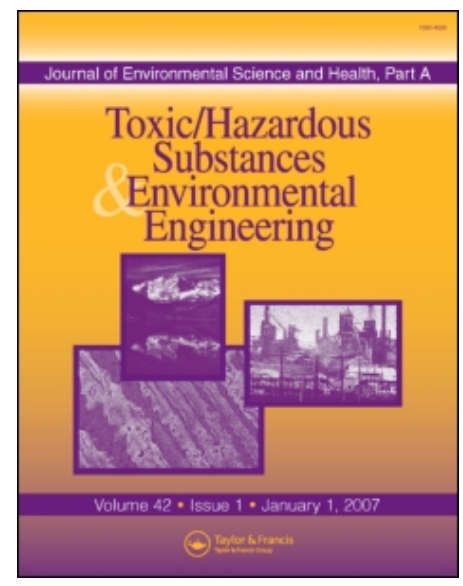

Journal of Environmental Science and Health, Part A

Publication details, including instructions for authors and subscription information:

http://www.informaworld.com/smpp/title content=t713597268

Study on a three-dimensional testing method coupling with a leaching behavior model for solidified waste matrix

Kuen-Shan Liu a; Kung-Cheh Li ${ }^{\text {a }}$

a Graduate Institute of Environmental Engineering National Taiwan University, Taipei, Taiwan

Online Publication Date: 01 May 2008

To cite this Article Liu, Kuen-Shan and Li, Kung-Cheh(2008)'Study on a three-dimensional testing method coupling with a leaching behavior model for solidified waste matrix',Journal of Environmental Science and Health, Part A,43:6,596 — 609

To link to this Article: DOI: 10.1080/10934520801893584

URL: http://dx.doi.org/10.1080/10934520801893584

PLEASE SCROLL DOWN FOR ARTICLE

\footnotetext{
Full terms and conditions of use: http://www.informaworld.com/terms-and-conditions-of-access.pdf

This article may be used for research, teaching and private study purposes. Any substantial or systematic reproduction, re-distribution, re-selling, loan or sub-licensing, systematic supply or distribution in any form to anyone is expressly forbidden.

The publisher does not give any warranty express or implied or make any representation that the contents will be complete or accurate or up to date. The accuracy of any instructions, formulae and drug doses should be independently verified with primary sources. The publisher shall not be liable for any loss, actions, claims, proceedings, demand or costs or damages whatsoever or howsoever caused arising directly or indirectly in connection with or arising out of the use of this material.
} 


\title{
Study on a three-dimensional testing method coupling with a leaching behavior model for solidified waste matrix
}

\author{
KUEN-SHAN LIU and KUNG-CHEH LI \\ Graduate Institute of Environmental Engineering, National Taiwan University, Taipei, Taiwan
}

\begin{abstract}
The objective of this study was to develop a three-dimensional leaching method to understand the diffusion behavior of a solidified waste matrix. A cylindrical solidified waste matrix with isotope lead compounds used as a tracer was used to demonstrate the diffusion phenomenon. The leaching test method was coupled with the mathematical diffusion model derived from Duhamel's theorem to control the time-dependent conditions and compute the mass diffusivity and mass generation rate constant of the target pollutants and also simulate the pollutants leached from solidified waste matrix. The simulation value is in fair agreement with experiment.
\end{abstract}

Keywords: Isotope, diffusion model, lead, fly ash, solidification

\section{Introduction}

When the public water supply system source is contaminated by lead, long-term health effects, such as brain and kidney damage, birth defects, are produced. ${ }^{[1]}$ Taiwan municipal solid waste incinerator (MSWI) fly ash contains lead oxide. After TCLP testing, the fly ash is classified as hazardous waste. MSWI fly ash must therefore be treated and tested before disposal. The characteristics of MSWI fly ash vary with the refuse source and the incinerator operating temperature. The solidifying agent, the leachant, the size of the waste matrix and leaching test method all affect the diffusion behavior, of the solidified waste matrix. According to previous studies, it was difficult to illustrate the waste matrix diffusion behavior, as solidified waste matrix contains large pores and the mass flux during leaching may not be proportional to the concentration gradient and may even be against it. ${ }^{[2]}$ Most solidified waste matrix diffusion models consider only one- or two-dimensional diffusion. ${ }^{[3-5]}$ As a result, mass diffusivity measurement methods lack reliability.

The diffusion behavior of a solidified waste matrix is a non-homogeneous diffusion problem. Accordingly, Duhamel's theorem, with the time-dependent boundary condition, and/or time-dependent condition, provides a convenient approach for mass diffusivity and mass generation rate constant measurements. ${ }^{[6,7]}$ The experimen-

Address correspondence to Kung-Cheh Li, Graduate Institute of Environmental Engineering, National Taiwan University, Taipei, Taiwan; E-mail: kcli@ntu.edu.tw

Received August 13, 2007. tal setup design and development of the three-dimension diffusion model in this study were based on Duhamel's Theorem.

The MSWI fly ash was mixed with lead isotope and the fly ash then was solidified and molded into cylindrical shapes. The molded solidified waste matrix was placed in a cylindrical container and a $\gamma$ detector instrument was applied to measure the lead isotope leached out of solidified waste matrix. The mass diffusivity $(\alpha)$ and mass generation rate constant $(\mathrm{k})$ of the solidified waste matrix were measured accurately under a unique leaching method design using a cylinder specimen and a cylindrical leaching vessel. The empirical mass diffusivity and mass generation rate constant are obtained using the least square method. The lead isotope release simulation from a solidified waste matrix can be calculated from the diffusion model using the empirical mass diffusivity and mass generation rate constant.

In general, solidification has been widely applied in hazardous waste management, including MSWI fly ash. When a solidification process is employed, the potential for contaminant loss from a solidified waste matrix is usually determined by leaching tests. Such leaching tests have been applied to characterize the impact for modeling steps. As mentioned above, most solidified waste matrix diffusion models consider only one- or two-dimensional diffusion, which does not allow the best leach phenomena description. Therefore, the objective of this study is to develop a threedimensional diffusion model based on Duhamel's theorem that provides a good simulation of the release mechanism to predict the long-term leaching behavior. This study also designed a leaching test method coupled with an experimental set-up that provides the required test data to verify the 
Table 1. Lead isotope leached from solidified waste matrix.

\begin{tabular}{|c|c|c|c|c|c|}
\hline \multicolumn{2}{|c|}{ Cement added (\%) } & \multirow{2}{*}{\multicolumn{2}{|c|}{$\begin{array}{l}\text { Isotope lead } \\
\text { release ( } m g \text { ) }\end{array}$}} & \multicolumn{2}{|c|}{$\begin{array}{c}\text { Isotope lead in } \\
\text { waste matrix ( } \mathrm{mg})\end{array}$} \\
\hline \multirow{2}{*}{$\begin{array}{l}\text { Leaching } \\
\text { interval }\end{array}$} & \multirow{2}{*}{$\begin{array}{c}\text { Leaching } \\
\text { duration }(s)\end{array}$} & & & \multirow{2}{*}{$\begin{array}{c}20 \\
1.05 E-01\end{array}$} & \multirow{2}{*}{$\begin{array}{c}40 \\
8.97 E-02\end{array}$} \\
\hline & & 20 & 40 & & \\
\hline 1 & 3600 & $1.28 \mathrm{E}-02$ & $9.59 \mathrm{E}-03$ & $9.17 \mathrm{E}-02$ & $8.01 \mathrm{E}-02$ \\
\hline 2 & 3600 & $6.52 \mathrm{E}-03$ & $3.27 \mathrm{E}-03$ & $8.52 \mathrm{E}-02$ & 7.69E-02 \\
\hline 3 & 3600 & 7.01E-03 & $4.75 \mathrm{E}-03$ & 7.82E-02 & $7.21 \mathrm{E}-02$ \\
\hline 4 & 3600 & $3.47 \mathrm{E}-03$ & $2.63 \mathrm{E}-03$ & 7.47E-02 & $6.95 \mathrm{E}-02$ \\
\hline 5 & 3600 & $2.92 \mathrm{E}-03$ & $2.41 \mathrm{E}-03$ & $7.18 \mathrm{E}-02$ & $6.71 \mathrm{E}-02$ \\
\hline 6 & 3600 & $1.85 \mathrm{E}-03$ & $4.05 \mathrm{E}-04$ & 6.99E-02 & $6.67 \mathrm{E}-02$ \\
\hline Lead leached $(\%)$ & & 33.07 & 25.69 & & \\
\hline
\end{tabular}

The volume of $\mathrm{pH} 0.89$ phosphoric acid (leachant) to the surface of the solidified waste matrix is 16 .

three-dimensional diffusion model. This procedure provides the confidence that the model performance is acceptable.

\section{Materials and methods}

\section{Preparation for testing a solidified waste specimen}

Fly ash was taken from the Taichung MSWI incinerator in Central Taiwan. A lead nitrate solution containing isotope $\mathrm{Pb}^{210} 28,362 \mathrm{~Bq}$ per $\mathrm{mL}$ in $3 \mathrm{M} \mathrm{HNO}_{3}$, was added to the fly ash. The ash was then mixed completely. MSWI fly ash contains lead oxide at a combustion temperature of $900^{\circ} \mathrm{C}$. Under this consideration, the mixed fly ash was put in an oven at $900^{\circ} \mathrm{C}$ for 10 hours. After cooling, the fly ash containing lead oxide with $\mathrm{Pb}^{210}$ isotope was solidified by adding water and $20 \%, 40 \%$ cement, respectively. The amount of fly ash, water and cement yielded a specimen with a water to solid ratio from 0.21 to 0.26 . The solidified waste matrix was molded into a cylinder with a diameter of $1 \mathrm{~cm}$ and a length of $4 \mathrm{~cm}$. Table 1 presents the leaching contents of the solidified waste matrix.

\section{Experimental apparatus and measurement procedure}

Through 15 days of incubation, the cylindrical solidified waste matrix was placed in a cylindrical leaching container with a diameter and height both of $5 \mathrm{~cm}$. Figure 1 shows the experimental apparatus. The unoccupied volume in the solidified waste matrix cylinder was used to contain $100 \mathrm{~mL}$ of leachant. The lead released from the waste matrix exhibits ion diffusion behavior at lower $\mathrm{pH}(\mathrm{pH} \leq 2) .{ }^{[8]}$ Therefore, phosphoric acid with $\mathrm{pH} 0.89$ was used as the leachant in this study. The ratio of the leachant volume to surface area of the solidified waste matrix cylinder was 16 . The leachant just covered the solidified waste matrix cylinder. The vessel was coved with a cap to minimized $\mathrm{CO}_{2}$ uptake. The solidified waste matrix height in the cylinder was kept just below the cylindrical container lip to prevent the leachant from overflowing during the experiment. Leachant replacement took place at the time intervals shown in Table 1. The overall research procedure for model verification is shown in Figure 2.

The amount of isotope lead that leached out of the solidified waste matrix cylinder was measured every hour within a six-hour experimental period. The leachate was collected at the time intervals shown in Table 1 . The amount of lead isotope that had leached out of the cylinder was measured with a $\gamma$ detector. The mass diffusivity $(\alpha)$ and mass generation rate constant $(\mathrm{k})$ can be directly calculated from the observed parameters.

Based on Duhamel's theorem, the empirical mass diffusivity $\left(\alpha^{\mathrm{T}}\right)$ of the solidified waste matrix cylinder was computed using the least-squares method. The empirical mass generation rate constant $\left(\mathrm{k}^{\mathrm{T}}\right)$ was also computed using the least square method and partly solved using the integration method. The calibrated diffusion model was developed using the empirical mass diffusivity, empirical mass generation rate constant and Bessel function root. Consequently, the simulated isotope lead released from a solidified waste matrix can be calculated from the calibrated diffusion model. The predicted lead isotope release from waste forms can be employed to verify the effectiveness of the diffusion model developed in this study. The diffusion model based on Duhamel's theorem is described in the following section.

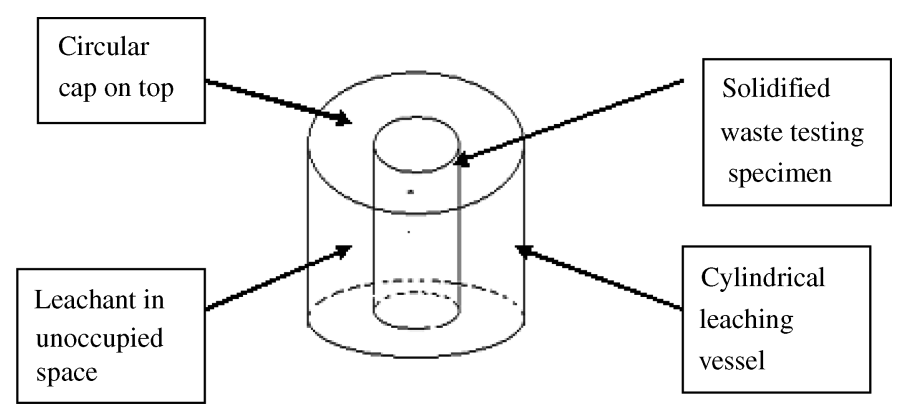

Fig. 1. Cylindrical leaching apparatus. 


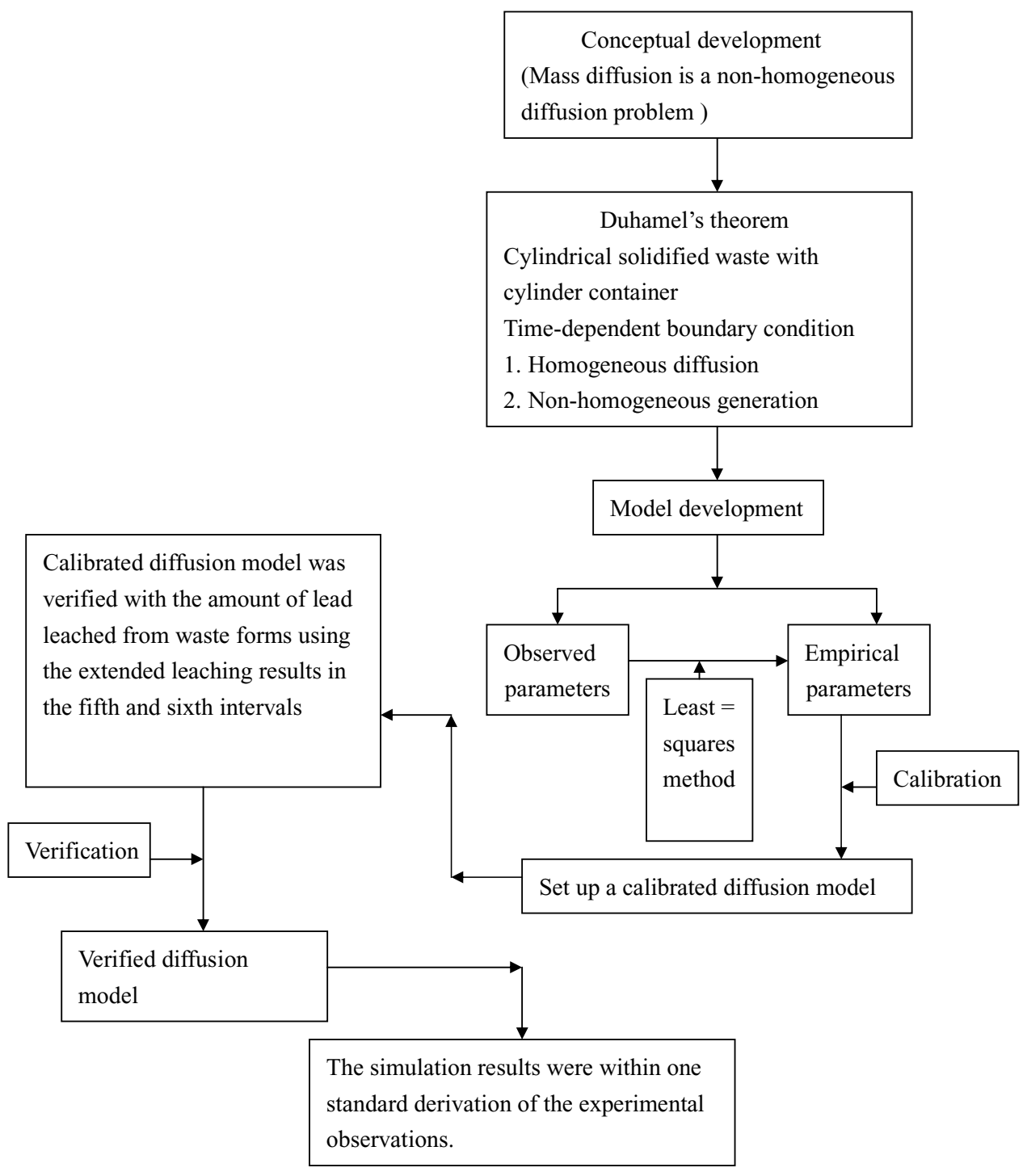

Fig. 2. Scheme of the research procedure.

\section{Model}

Although a number of solidified waste diffusion models have been developed, they do not include all of the diffusion phenomena. The model developed by Poon and $\mathrm{Chen}^{[9]}$ uses leachant pressure flow in the leaching process. The ANS 16.1 (American Nuclear Society, 1986) leaching test only considers the pollutants occurring on the perpendicular edge of the solidified waste. ${ }^{[10]}$ There is a limitation to the ANS 16.1 leaching test. The model developed by Godbee and Joy ${ }^{[11]}$ focused on the solidified waste surface to leachant volume ratio, the dissolution of the cement component and pore structure. These models may caused the excess or retard the components diffused from solidified waste. Although numerous leaching test methods are available to evaluate the degree of stabilization/solidification (S/S), no single test method can de- scribe the complex leaching behavior of the solidified waste. The exact solution for the diffusion equation depends on the initial and boundary conditions. Reducing the diffusion effect is the reason why a three-dimensional mathematical method with the test specimen and leaching vessel having the same shape is used to model diffusion behavior in this study.

Because solidified waste diffusion is a non-homogeneous problem, it can be divided into a set of simple problems solved using the separation of variables method. ${ }^{[7]} \mathrm{Al}-$ though leaching can proceed through several concurrent mechanisms, the long-term leaching characteristics of solidified treated wastes are controlled by diffusion. ${ }^{[12]}$ The dissolution, sedimentation, desoption/adsorption, and erosion do not significantly affect the leaching. The mathematical diffusion model for the solidified waste matrix cylinder is set up in this study as follows: 


\section{The homogeneous diffusion parts}

Assume that a time varying concentrated lead isotope, $C$ $(t)$, in a solidified waste matrix has no discontinuities. An expression for the lead isotope concentration distribution $C(r, t)$ in the solidified waste matrix cylinder for times $t>$ 0 , the mathematical formulation of this problem is given by

$$
\begin{array}{ll}
\frac{\partial^{2} C(r, t)}{\partial r^{2}}+\frac{1}{r} \frac{\partial C(r, t)}{\partial r}=\frac{1}{\alpha} \frac{\partial C(r, t)}{\partial t} \text { in } 0 \leq r<b, t>0 \\
C(r, t)=C(t) \quad \text { at } r=b, t>0 & \text { (1a) } \\
C(0, t)=0 \quad \text { for } t=0 \quad \text { in } 0 \leq r \leq b & \text { (1c) }
\end{array}
$$

where $\mathrm{C}(0, \mathrm{t})$ : initial lead isotope concentration in the solidified waste matrix

$$
\begin{aligned}
& C(r, t)=\text { time varying lead isotope concentration in the } \\
& r \quad=\text { radius of the solidified waste specimen } \\
& \alpha \quad=\text { mass diffusivity }\left(\mathrm{cm}^{2} / \mathrm{s}\right) \text { of the lead isotope in } \\
& \text { the cylindrical solidified waste } \\
& t=\text { leaching time(s) }
\end{aligned}
$$

In the initial step toward solution using Duhamel's theorem, we solve first the problem when $C(t)$ is the unit. Denoting this result by $\Phi=\Phi(r, t)$, the auxiliary problem is taken as

$$
\begin{aligned}
& \frac{\partial^{2} \Phi(r, t)}{\partial r^{2}}+\frac{\partial \Phi(r, t)}{r \partial r}=\frac{1}{\alpha} \frac{\partial \Phi(r, t)}{\partial t} \quad \text { in } 0 \leq r<b, t>0 \\
& \Phi=1 \quad \text { at } r=b \quad t>0 \\
& \Phi=0 \quad \text { for } t=0 \quad \text { in } 0 \leq r \leq b
\end{aligned}
$$

Assuming that $C(r, t)$ is differentiable, this is the superposition integral that gives the desired solution in terms of the basic $\Phi(r, t)$. According to Duhamel's theorem, an alternative form is obtained through integration by parts formulated as follows:

$$
\begin{aligned}
& C(r, t)=\int_{0}^{t} C(\tau) \frac{\partial \Phi(r, t-\tau)}{\partial t} d \tau(0 \leq r \leq b) \text { or } \\
& C(r, t)=-\int_{\tau=0}^{t} C(t) \frac{\partial \Phi(r, t-\tau)}{\partial \tau} d \tau
\end{aligned}
$$

$\tau$ is dimensionless time or Fourier number $\tau=\frac{\alpha t}{b^{2}}$ Let

$$
\psi(r, t)=\frac{2}{b} \sum_{m=1}^{\infty} e^{-\alpha \beta_{m}^{2} t} \frac{J_{0}\left(\beta_{m} r\right)}{\beta_{m} J_{1}\left(\beta_{m} r\right)}
$$

Let Equation 4 be the problem solution for the solidified waste matrix cylinder.

The $\beta_{m}$ values in Equation 4 are the positive roots of the Bessel function and $J_{0}\left(\beta_{m} b\right)=0, J_{0}\left(\beta_{m} \mathrm{r}\right), J_{1}\left(\beta_{m} r\right)$ are the zero and first roots of the first kind of the Bessel function.
For $0 \leq r \leq b$, initially at concentration unity and for times $t>0$. The boundary surface at $r=b$ is kept at zero concentration. Let the constant initial concentration be $C(r, t)$ $=1$. The solution for $\psi(r, t)=\frac{2}{b} \sum_{m=1}^{\infty} e^{-\alpha \beta_{m}^{2} t} \frac{J_{0}\left(\beta_{m} r\right)}{\beta_{m} J_{1}\left(\beta_{m} r\right)}$ is then obtainable as

$$
C(r, t)=\frac{2 C_{0}}{b} \sum_{m=1}^{\infty} e^{-\alpha \beta_{m}^{2} t} \frac{J_{0}\left(\beta_{m} r\right)}{\beta_{m} J_{1}\left(\beta_{m} r\right)}
$$

The solution $\Phi(r, t)$ for the auxiliary problem, Equation 2 is obtainable from the solution $\psi(r, t)$, given Equation 5 as follows:

$$
\Phi(r, t)=1-\psi(r, t)=1-\frac{2}{b} \sum_{m=1}^{\infty} e^{-\alpha \beta_{m}^{2} t} \frac{J_{0}\left(\beta_{m} r\right)}{\beta_{m} J_{1}\left(\beta_{m} b\right)}
$$

Introducing Equation 6 into Equation 3, the solution for the Equation 1 problem can be derived as

$$
\begin{aligned}
C(r, t)= & \frac{2 \alpha}{b} \sum_{m=1}^{\infty} e^{-\alpha \beta_{m}^{2} t} \beta_{m} \frac{J_{0}\left(\beta_{m} r\right)}{J_{1}\left(\beta_{m} b\right)}\left[C(0) e^{-\alpha \beta_{m}^{2} t}\right. \\
& \left.+e^{-\alpha \beta_{m}^{2}(t-\tau)} d C(\tau)\right]
\end{aligned}
$$

The $\beta_{m}$ values are the positive roots of the Bessel function $\mathbf{J}_{0}\left(\beta_{m} b\right)=0$. To obtain an alternative form of Equation 7, time integration is performed by parts to obtain the following equation.

$$
\begin{aligned}
C(r, t)= & C(t) \frac{2}{b} \sum_{m=1}^{\infty} e^{-\alpha \beta_{m}^{2} t} \frac{J_{0}\left(\beta_{m} r\right)}{\beta_{m}\left(\beta_{m} b\right)} \\
& -\frac{2}{b} \sum e^{-\alpha \beta_{m}^{2} t} \frac{J_{0}\left(\beta_{m} r\right)}{\beta_{m} J_{1}\left(\beta_{m} b\right)} \\
& \times\left(C(0) e^{-\alpha \beta_{m}^{2} t}+\int_{0}^{t} e^{-\alpha \beta_{m}^{2}(t-\tau)} d C(\tau)\right)
\end{aligned}
$$

The intermediate steps of Equation 8 are described in Appendix A, Part A.

We note that the solution for Equation 5 for $\mathrm{t}=0$ should be equal to the initial concentration $\psi(r, o)=1$; thus, we have

$$
1=\frac{2}{b} \sum_{m=1}^{\infty} e^{-\alpha \beta_{m}^{2} t} \frac{J_{0}\left(\beta_{m} r\right)}{\beta_{m} J_{1}\left(\beta_{m} r\right)}
$$

Which gives the desired closed-form expression for the first series on the right-hand side of Equation 8, the solution for Equation 8 is then written as

$$
\begin{aligned}
C(r, t)= & C(t)-\frac{2}{b} \sum_{m=1}^{\infty} e^{-\alpha \beta_{m}^{2} t} \frac{J_{0}\left(\beta_{m} r\right)}{\beta_{m} J_{1}\left(\beta_{m} b\right)} \\
& \times\left(C(0) e^{-\alpha \beta_{m}^{2} t}+\int_{0}^{t} e^{-\alpha \beta_{m}^{2}(t-\tau)} d C(\tau)\right)
\end{aligned}
$$

The solution given in this form clearly shows that $C(r, t)$ $=C(t)$ at $r=b$.

Let $e^{-\alpha \beta_{m}^{2} t} C(0)=0$. Differentiate $\int_{0}^{t} e^{-\alpha \beta_{m}^{2}(t-\tau)} d C(\tau)$ in Equation 10 and time integrate it by parts. An experimental 
(observed) mass diffusivity equation comes to Equation 11 as the following step.

$$
\begin{aligned}
& \int_{0}^{t} e^{-\alpha \beta_{m}^{2}(t-\tau)} d C(\tau)=\int_{0}^{t} e^{-\alpha \beta_{m}^{2}(t-\tau)} \frac{d C(\tau)}{d \tau} d \tau \\
& \int_{0}^{t} e^{-\alpha \beta_{m}^{2}(t-\tau)} \frac{d C(\tau)}{d \tau} d \tau=\int_{0}^{t}-2 \alpha \beta_{m}^{2} \tau \times e^{-\alpha \beta_{m}^{2}(t-\tau)} C(\tau) d \tau \\
& \quad=-2 \alpha \beta_{m}^{2} \tau \times\left. e^{-\alpha \beta_{m}^{2}(t-\tau)} C(\tau)\right|_{0} ^{t} \\
& \quad=-2 \alpha \beta_{m}^{2} \times t \times e^{-\alpha \beta_{m}^{2}(t-t)} C(t)-2 \alpha \beta_{m}^{2} \times 0 \times e^{-\alpha \beta_{m}^{2} t} C(0)
\end{aligned}
$$

Then

$$
\begin{aligned}
C(r, t) & =C(t)-\frac{2}{b} \sum_{m=1}^{\infty} \frac{J_{0}\left(\beta_{m} r\right)}{\beta_{m} J_{1}\left(\beta_{m} b\right)} \times\left(-2 \alpha \beta_{m}^{2} \times t \times C(t)\right) \\
\alpha & =\frac{C(r, t)-C(t)}{\frac{4}{b} C(t) \times t \sum_{m=1}^{\infty} \frac{J_{0}\left(\beta_{m}^{r}\right)}{J_{1}\left(\beta_{m} b\right)} \times \beta_{m}}
\end{aligned}
$$

It shows that the mass diffusivity is a time-dependent problem.

\section{The non-homogeneous generation rate parts}

This is considered a non-homogeneous problem in which the generation term and the non-homogeneous parts of the boundary condition function do not depend on time. It is assumed that lead isotope diffuses into the leachant from the cylindrical container at a constant rate $g(t)$ per unit volume with no discontinuities and a mass generation rate constant $(k)$. The mathematical formulation for the concentration distribution $C(r, t)$ in the solidified waste matrix cylinder is given by:

$$
\begin{aligned}
& \frac{\partial^{2} C(r, t)}{\partial r^{2}}+\frac{1}{r} \frac{\partial C(r, t)}{\partial r}+\frac{g(t)}{k} \\
& \quad=\frac{1}{\alpha} \frac{\partial C(r, t)}{\partial t} \quad \text { in } 0 \leq r<b \quad t>0 \\
& C(r, t)=0 \quad \text { at } r=b \quad t>0 \\
& C(0, t)=0 \quad \text { for } t=0 \quad \text { in } 0 \leq r \leq b
\end{aligned}
$$

The auxiliary problem is taken as

$$
\begin{aligned}
& \frac{\partial^{2} \Phi(r, t)}{\partial r^{2}}+\frac{1}{r} \frac{\partial \Phi(r, t)}{\partial r}+\frac{1}{k}=\frac{1}{\alpha} \frac{\partial \Phi(r, t)}{\partial t} \text { in } \\
& 0 \leq r<b, t>0 \\
& \Phi=0 \text { at } r=b \quad t>0 \\
& \Phi=0 \text { for } t=0 \text { in } 0 \leq r \leq b
\end{aligned}
$$

The solution for Equation 12 is related to the solution for the auxiliary problem. Using Duhamel's theorem, Equation 13 can be expressed as

$$
C(r, t)=\int_{\tau=0}^{t} g(\tau) \frac{\partial \Phi(r, t-\tau)}{\partial t} d \tau
$$

The solution for the auxiliary problem Equation 13 is given as follows:

$$
\frac{\partial C(r, t)}{\partial r^{2}}+\frac{1}{r} \frac{\partial C(r, t)}{\partial r}+\frac{1}{k}
$$

$$
\begin{gathered}
=\frac{1}{\alpha} \frac{\partial C(r, t)}{\partial t} \quad \text { in } 0 \leq r<b \quad t>0 \\
C(r, t)=0 \text { at } r=b \quad t>0 \\
C(r, t)=C(t) \quad \text { for } t=0 \quad \text { in } 0 \leq r \leq b
\end{gathered}
$$

The lead isotope leached from the solidified waste matrix cylinder is determined as a function of the cylinder diameter and time. In this problem, it is convenient to express the lead isotope leached from the solid waste matrix as the sum of two distributions. The first distribution is the limiting steady-state distribution, (independent of $t$ ), after the transient effects have become negligible. The second distribution represents the transient distribution (which must then approach zero as $t$ increases indefinitely). Thus, writing

$$
C(r, t)=C_{s}(r, t)+C_{h}(r, t)
$$

$\mathrm{C}_{h}(r, t)$ is a particular solution for

$$
\frac{\partial^{2} C(r, t)}{\partial r^{2}}+\frac{\partial(r, t)}{r \partial r}+\frac{g(t)}{k}=\frac{1}{\alpha} \frac{\partial(r, t)}{\partial t}
$$

The function of $C_{h}(r, t)$ must be determined in such a way that it vanishes when $t \rightarrow \infty C_{h}(r, \infty)=0$ and so that the sum $C_{s}(r, t)+C_{h}(r, t)$ satisfies the initial steady-state condition and transient conditions, respectively. $C_{h}(r, t)$ must vanished at $r=0$ and $r=b$ for all positive t values.

$$
C_{s}(0, t)=0 \quad \text { and } \quad \mathrm{C}_{h}(r, t)=0
$$

Therefore, the transient lead isotope concentration distribution satisfies the homogeneous end conditions. The steadystate lead isotope concentration distribution was separated first for this reason.

The steady-state problem is readily solved using

$$
C_{s}(r, t)=\frac{g(t)}{4 k}\left(b^{2}-r^{2}\right)
$$

The homogeneous problem is obtained from equation

$$
\begin{aligned}
& C_{h}(r, t)=\frac{2}{b^{2}} \sum_{m=1}^{\infty} e^{-\alpha \beta_{m}^{2} t} \frac{J_{0}\left(\beta_{m} r\right)}{J_{1}^{2}\left(\beta_{m} b\right)} \\
& \times \int_{0}^{b} r^{\prime} J_{0}\left(\beta_{m} r^{\prime}\right)\left[C\left(r^{\prime}\right)-C_{s}\left(r^{\prime}\right)\right] d r^{\prime}
\end{aligned}
$$

Where the $\beta_{m}$ values are the roots of Bessel function $J_{0}\left(\beta_{m} r\right)$.

The intermediate steps of Equation 18 are described in Appendix A, Part B.

Equations 17 and 18 are introduced into Equation 15 and some integrals are performed. We then obtain the following equation

$$
\begin{gathered}
C(r, t)=\frac{g(t)\left(b^{2}-r^{2}\right)}{4 k}-\frac{2 g(t)}{b k} \sum_{m=1}^{\infty} e^{-\alpha \beta_{m}^{2} t} \frac{J_{0}\left(\beta_{m} r\right)}{\beta_{m}^{3} J_{1}\left(\beta_{m} b\right)} \\
+\frac{2}{b^{2}} \sum_{m=1}^{\infty} e^{-\alpha \beta_{m}^{2} t} \frac{J_{0}\left(\beta_{m} r\right)}{J_{1}^{2}\left(\beta_{m} b\right)} \int_{0}^{b} r^{\prime} J_{0}\left(\beta_{m} r^{\prime}\right) C\left(r^{\prime}\right) d r^{\prime}
\end{gathered}
$$


For the Equation 19 solution, by setting $g(t)=1$ and $C(r, t)$ $=0$, we find

$$
\Phi(r, t)=\frac{b^{2}-r^{2}}{4 k}-\frac{2}{b k} \sum_{m=1}^{\infty} e^{-\alpha \beta_{m}^{2} t} \frac{J_{0}\left(\beta_{m} r\right)}{\beta_{m}^{3} J_{1}\left(\beta_{m} b\right)}
$$

The $\beta_{m}$ values are the positive roots of $J_{0}\left(\beta_{m} b\right)=0$.

Introducing Equation 21 into Equation 14, the solution is obtained as follows:

$$
\begin{aligned}
C(r, t) & =\int_{\tau=0}^{t} g(\tau) \frac{\partial \Phi(r, t-\tau)}{\partial t} d \tau \\
& =-\frac{2}{b k} \times-\alpha \beta_{m}^{2} \int_{\tau=0}^{t} g(\tau) e^{-\alpha \beta_{m}^{2}(t-\tau)} \frac{J_{0}\left(\beta_{m} r\right)}{\beta_{m}^{3} J_{1}\left(\beta_{m} b\right)} d \tau \\
& =\frac{2 \alpha \beta_{m}^{2}}{b k} \sum_{m=1}^{\infty} e^{-\alpha \beta_{m}^{2} t} \frac{J_{0}\left(\beta_{m} r\right)}{\beta_{m}^{3} J_{1}\left(\beta_{m} b\right)} \int_{0}^{t} g(\tau) e^{\alpha \beta_{m}^{2} \tau} d \tau \\
& =\frac{2 \alpha}{b k} \sum_{m=1}^{\infty} \frac{J_{0}\left(\beta_{m} r\right)}{\beta_{m} J_{1}\left(\beta_{m} b\right)} * g(t) \int_{\tau=0}^{t} e^{-\alpha \beta_{m}^{2} t\left(1-\frac{\tau}{t}\right)} d \tau
\end{aligned}
$$

The mass generation rate constant can be obtained as Equation 23 .

$$
k=\frac{2 \alpha}{b C(r, t)} \sum_{m=1}^{\infty} \frac{J_{0}\left(\beta_{m} r\right)}{\beta_{m} J_{1}\left(\beta_{m} b\right)} * g(t) \int_{\tau=0}^{t} e^{-\alpha \beta_{m}^{2} t\left(1-\frac{\tau}{t}\right)} d \tau
$$

\section{Solution}

Both the mass diffusivity and mass generation rate constant are directly computed using Equations 11 and 23 in every leaching time interval, respectively. The mass diffusivity and mass generation rate could be considered to remain constant throughout the overall leaching procedure. Arranging the model equation and using the least square method to find the empirical control parameters, a suitable $\beta_{m}$ value (Bessel function root) will direct the observed mass diffusivity and empirical mass diffusivity. The lead isotope released from the waste matrix predicated using this model is close to the experimental measurements with an appropriate $\beta_{m}$ value. The computed processes are demonstrated next.

The empirical mass diffusivity $\left(\alpha^{\mathrm{T}}\right)$ is calculated from equation 11 using the least square method as follows.

$$
\begin{aligned}
y & =\frac{C(r, t)-C(t)}{C(t)} * \frac{1}{\frac{2}{b} \sum_{m=1}^{\infty} \frac{J_{0}\left(\beta_{m} r\right)}{\beta_{m} J_{1}\left(\beta_{m} b\right)} \beta_{m}^{2}}=\alpha * t \\
{[\delta \delta] } & =\sum\left\{y_{i}-\alpha * t_{i}\right\}^{2}=\operatorname{minimum} i=1,2,3,4 \\
\frac{\partial[\delta \delta]}{\partial y} & =2 * y_{i}-2 * \alpha * t_{i}=0 \\
\alpha^{T} & =\frac{\left[y_{i}\right]}{\left[t_{i}\right]}
\end{aligned}
$$

[ ] represents the summation of $\mathrm{n}$ observed values.

After obtaining $\alpha^{\mathrm{T}}$, the empirical mass generation rate constant $\left(\mathrm{k}^{\mathrm{T}}\right)$ can also be calculated from Equation $23 \mathrm{using}$ the least-squares method as follows.

$$
\begin{array}{rl}
k=2 & *\left(\frac{C(r, t)-C(t)}{C(t) * t} * \frac{1}{\frac{2}{b} \sum_{m=1}^{\infty} \frac{J_{0}\left(\beta_{m} r\right)}{\beta_{m} J_{1}\left(\beta_{m} b\right)} \beta_{m}^{2}}\right) \\
& * g(t) * \frac{1}{b * C(r, t)} * \sum_{m=1}^{\infty} \frac{J_{0}\left(\beta_{m} r\right)}{\beta_{m} J_{1}\left(\beta_{m} b\right)} \int_{\tau=0}^{t} e^{-\alpha \beta_{m}^{2} t\left(1-\frac{\tau}{t}\right)} d \tau \\
k * t & =2 *\left(\frac{C(r, t)-C(t)}{C(t)} * \frac{1}{\frac{2}{b} \sum_{m=1}^{\infty} \frac{J_{0}\left(\beta_{m} r\right)}{\beta_{m} J_{1}\left(\beta_{m} b\right)} \beta_{m}^{2}}\right) * g(t) \\
* \frac{1}{b * C(r, t)} * \sum_{m=1}^{\infty} \frac{J_{0}\left(\beta_{m} r\right)}{\beta_{m} J_{1}\left(\beta_{m} b\right)}\left(e^{-\alpha^{T} \beta_{m}^{2} t\left(1-\frac{t}{t}\right)}-e^{-\alpha^{T} \beta_{m}^{2} t\left(1-\frac{o}{t}\right)}\right) \\
k * t=2 *\left(\frac{C(r, t)-C(t)}{C(t)} * \frac{1}{\frac{2}{b} \sum_{m=1}^{\infty} \frac{J_{0}\left(\beta_{m} r\right)}{\beta_{m} J_{1}\left(\beta_{m} b\right)} \beta_{m}^{2}}\right) * g(t) \\
* \frac{1}{b * C(r, t)} * \sum_{m=1}^{\infty} \frac{J_{0}\left(\beta_{m} r\right)}{\beta_{m} J_{1}\left(\beta_{m} b\right)}\left(e^{0}-e^{-\alpha^{T} \beta_{m}^{2} t}\right)
\end{array}
$$

Let

$$
\begin{aligned}
& Z=2 *\left(\frac{C(r, t)-C(t)}{C(t)} * \frac{1}{\frac{2}{b} \sum_{m=1}^{\infty} \frac{J_{0}\left(\beta_{m} r\right)}{\beta_{m} J_{1}\left(\beta_{m} b\right)} \beta_{m}^{2}}\right) \\
& \quad * g(t) \frac{1}{b * C(r, t)} * \sum_{m=1}^{\infty} \frac{J_{0}\left(\beta_{m} r\right)}{\beta_{m} J_{1}\left(\beta_{m} b\right)}\left(1-e^{-\alpha^{T} \beta_{m}^{2} t}\right)=k * t \\
& Z=\left(\frac{[C(r, t)-C(t)]^{2}}{C(r, t) * C(t)} * \frac{1}{\sum_{m=1}^{\infty} \frac{J_{0}\left(\beta_{m} r\right)}{\beta_{m} J_{1}\left(\beta_{m} b\right)} \beta_{m}^{2}}\right) \\
& \quad * \sum_{m=1}^{\infty} \frac{J_{0}\left(\beta_{m} r\right)}{\beta_{m} J_{1}\left(\beta_{m} b\right)}\left(1-e^{-\alpha^{T} \beta_{m}^{2} t}\right)=k * t \\
& {[\delta \delta]=\sum\left\{Z_{i}-k * t_{i}\right\}^{2}=\text { Minimum } i=1,2,3,4} \\
& \frac{\partial[\delta \delta]}{\partial Z}=2 * Z_{i}-2 * k * t_{i}=0 \\
& k^{T}=\frac{\left[Z_{i}\right]}{[t]}
\end{aligned}
$$

Using $\alpha^{\mathrm{T}}, k^{\mathrm{T}}$ and $J_{0}\left(\beta_{m} \mathrm{r}\right), \mathrm{J}_{1}\left(\beta_{m} \mathrm{~b}\right), \beta_{m}$ from Ozisik ${ }^{[7]}$ the isotope lead release from waste matrix can be simulated using the following model:

$$
G^{T}(t)=\frac{k^{T} * b * C(r, t)}{2 * \alpha^{T} * \sum_{m=1}^{\infty} \frac{J_{0}\left(\beta_{m} r\right)}{\beta_{m} J_{1}\left(\beta_{m} r\right)} \int_{\tau=0}^{t} e^{-\alpha^{T} \beta_{m}^{2} t\left(1-\frac{\tau}{t}\right)} d \tau}
$$

\section{Model validation}

Duhamel's theorem for the solution to problems with timedependent boundary condition function and/or mass generation is suitable for the diffusion solution in this study. Basically, the lead isotope leached from the solidified waste matrix cylinder is a function of the cylinder diameter and time. Hence, Duhamel's theorem was applied to simulate the subsequent diffusion phenomena. The diffusion model can be calibrated based on this theory, using the empirical 
diffusivity, empirical mass generation rate constant and Bessel function roots. The predicated lead isotope released from the solidified waste matrix could be calculated from the calibrated and verified diffusion model. The calibrated and verified diffusion model can be developed as follows:

$$
G^{T}\left(t_{i}\right)=\frac{k^{T} * b *\left(C(o, t)-\sum_{0}^{i} G^{T}\left(t_{i-1}\right)\right)}{2 * \alpha^{T} * \sum_{m=1}^{\infty} \frac{J_{0}\left(\beta_{m}^{r}\right)}{\beta_{m} J_{1}\left(\beta_{m} r\right)} \int_{\tau=0}^{t} e^{-\alpha^{T} \beta_{m}^{2} t\left(1-\frac{\tau}{t}\right)} d \tau}
$$

$i \quad=$ leaching interval

$G^{T}\left(t_{i}\right)=$ Lead isotope release simulation from waste matrix at i leaching interval

$C(0, t)=$ Initial lead isotope concentration in the solidified waste matrix

$G^{T}\left(t_{0}\right)=0$

$\alpha^{T} \quad=$ Empirical mass diffusivity $\left(\mathrm{cm}^{2} / \mathrm{s}\right)$

$k^{T}=$ Empirical mass generation rate constant $(1 / \mathrm{s})$

The $\alpha^{T}$ and $k^{T}$ obtained using the least square method for the first, second, third and fourth leaching result intervals were used to established the calibrated model. The lead isotope released from the waste matrix in the fifth and sixth intervals were used to verify the diffusion model (Equation 27). The correspondence between the simulated and measured mass release rates was compared to assess the model acceptance. The criterion for model calibration and verification was the simulation results within one standard derivation of the experimental observations. A sample calculation for empirical mass diffusivity, empirical mass generation rate constant and simulated isotope lead release is demonstrated in Appendix B.

\section{Results and discussion}

Table 1 shows that the amount of lead isotope leached out of a solidified waste matrix cylinder with $\mathrm{pH} 0.89$ phosphoric acid leachant was between $25.69 \%$ and $33.07 \%$ within 6 hours. At the first hour of leaching, the amount of lead isotope that leached out of the solidified waste matrix was the greatest. In the next 4 hours, the amount of lead isotope that leached out of the solidified waste matrix decreased. After the fifth hour, the leaching rate was dramatically reduced.
The amount of lead leached from the solidified waste matrix decreased with the leaching time as shown in Table 1.

Table 1 also demonstrates the amount of lead isotope leached out of the cylinder solidified waste matrix to which $20 \%$ cement addition was greater than that of $40 \%$ cement additions. It also reveals that the amount of lead isotope that leached out of the solidified waste matrix coincided with the amount of added cement in the solid under the same boundary conditions on every leaching test. These results verified the lead isotope for tracing the leaching behavior of a solidified waste matrix is a promising method.

Table 2 indicates that the observed mass diffusivity $(\alpha)$ (Equation 11) of the cylindrical solidified waste matrix using $\mathrm{pH} 0.89$ phosphoric acid as the leachant with the addition of $20 \%, 40 \%$ cement were in the order of $10 \mathrm{E}-8$ at the six leaching test time intervals. The observed mass generation rate constant $(\mathrm{k})$ (Equation 23 ) for the cylindrical solidified waste matrix using $\mathrm{pH} 0.89$ phosphoric acid as the leachant with the addition of $20 \%, 40 \%$ cement were in the range of $10 \mathrm{E}-8$ and $10 \mathrm{E}-12$. A calibrated diffusion model using the least square method to determine the empirical mass diffusivity (Equation 24) in the same order as the observed values is shown in Table 3. A Bessel function root control value is present in this diffusion model. The lead isotope release simulation was performed using the diffusion model. After obtaining the empirical mass diffusivity, the empirical mass generation rate constant (Equation 25) could also be easily computed from the diffusion model using the least-squares method using empirical mass diffusivity, isotope lead release and Bessel function root. Table 4 and Figures 3 and 4 demonstrate that the lead isotope release from solidified waste matrices simulation with $\mathrm{pH} 0.89$ phosphoric acid leachant using the calibrated and verified diffusion model (Equation 27) has good correspondence between the measured and simulated values in this study, as shown in Table 4. It is quite obvious that the simulated lead isotope releases were within one standard deviation of the observations, as shown in Figures 3 and 4. A model results comparison with the experimental data showed that the lead isotope leached out of the solidified waste matrix corresponding to the various amounts of cement added to the waste could be acceptable.

Table 2. Observed mass diffusivity and mass generation rate constant from the experimental results.

\begin{tabular}{|c|c|c|c|c|c|}
\hline \multicolumn{2}{|c|}{ Cement added (\%) } & \multicolumn{2}{|c|}{$\begin{array}{l}\text { Observed mass diffusivity } \\
\qquad(\alpha)\left(\mathrm{cm}^{2} / \mathrm{s}\right)\end{array}$} & \multicolumn{2}{|c|}{$\begin{array}{l}\text { Observed mass generation } \\
\text { rate constant }(k)(1 / s)\end{array}$} \\
\hline $\begin{array}{c}\text { Leaching } \\
\text { interval }\end{array}$ & $\begin{array}{c}\text { Leaching } \\
\text { duration }(s)\end{array}$ & 20 & 40 & 20 & 40 \\
\hline 1 & 3600 & $9.60 \mathrm{E}-08$ & $1.37 \mathrm{E}-08$ & $1.71 \mathrm{E}-08$ & $3.63 \mathrm{E}-10$ \\
\hline 2 & 3600 & $5.26 \mathrm{E}-08$ & 2.92E-08 & $3.28 \mathrm{E}-09$ & $6.51 \mathrm{E}-10$ \\
\hline 3 & 3600 & $6.16 \mathrm{E}-08$ & $4.53 \mathrm{E}-08$ & 4.61E-09 & $2.5 \mathrm{E}-09$ \\
\hline 4 & 3600 & $3.19 \mathrm{E}-08$ & $2.60 \mathrm{E}-08$ & $7.06 \mathrm{E}-10$ & $5.1 \mathrm{E}-10$ \\
\hline 5 & 3600 & $2.80 \mathrm{E}-08$ & $2.47 \mathrm{E}-08$ & $4.96 \mathrm{E}-10$ & $4.53 \mathrm{E}-10$ \\
\hline 6 & 3600 & $1.82 \mathrm{E}-08$ & 4.17E-09 & $1.43 \mathrm{E}-10$ & $2.29 \mathrm{E}-12$ \\
\hline
\end{tabular}


Table 3. Empirical mass diffusivity $\left(\alpha^{T}\right)$ and mass generation rate constant $\left(K^{T}\right)$ computed from the least-squares method.

\begin{tabular}{|c|c|c|c|c|c|}
\hline \multicolumn{3}{|c|}{ Empirical mass diffusivity $\left(\mathrm{cm}^{2} / \mathrm{s}\right)$} & \multicolumn{3}{|c|}{ Empirical mass generation rate constant $(1 / s)$} \\
\hline \multicolumn{3}{|c|}{$Y=\frac{C(r, t)-C(t)}{C(t)} * \frac{1}{\frac{2}{b} \sum_{m=1}^{\infty} \frac{J_{0}\left(\beta_{m} r^{r}\right)}{\beta_{m} J_{1}\left(\beta_{m} b\right)} \beta_{m}^{2}}=\alpha * t$} & \multicolumn{3}{|c|}{$Z=\left(\frac{[C(r, t)-C(t)]^{2}}{C(r, t) * C(t)} * \frac{1}{\sum_{m=1}^{\infty} \frac{J_{0}\left(\beta_{m} r\right)}{\beta_{m} J_{1}\left(\beta_{m}\right)} \beta_{m}^{2}}\right) * \sum_{m=1}^{\infty} \frac{J_{0}\left(\beta_{m} r\right)}{\beta_{m} J_{1}\left(\beta_{m} b\right)}\left(1-e^{-\alpha \beta_{m}^{2} t}\right)=K * t$} \\
\hline Y1 & $2.86 \mathrm{E}-04$ & $2.46 \mathrm{E}-04$ & Z1 & $3.00 \mathrm{E}-06$ & $1.71 \mathrm{E}-06$ \\
\hline $\mathrm{Y} 2$ & $1.57 \mathrm{E}-04$ & $8.72 \mathrm{E}-05$ & $\mathrm{Z} 2$ & $1.87 \mathrm{E}-06$ & $4.57 \mathrm{E}-07$ \\
\hline Y4 & $5.02 \mathrm{E}-08$ & $3.79 \mathrm{E}-08$ & $k^{T}=\frac{[2]}{[t]}$ & $6.91 \mathrm{E}-10$ & $3.09 \mathrm{E}-10$ \\
\hline
\end{tabular}

[ ] represents the summation of n observed values.

$\sum_{m=1}^{\infty} \frac{J_{0}\left(\beta_{m} r\right)}{\beta_{m} J_{1}\left(\beta_{m} b\right)} \beta_{m}^{2}=122 \quad \beta_{m}=22$.

This study validated that Duhamel's Theorem can be used to determine the mass diffusivity of a solidified waste matrix and also calculate the mass generation rate of a specific solidified waste matrix. It was also proven that phosphoric acid is suitable for measuring the mass diffusivity $(\alpha)$ and mass generation rate constant $(\mathrm{k})$ for a solidified waste matrix cylinder. Thus, the diffusion model coupled with the experimental design developed in this study is a very appropriate instrument for understanding the leaching behavior of solidified waste.

The experimental apparatus is this study was a solidified waste matrix cylinder placed inside a cylindrical leaching vessel that reflected the time-dependent boundary conditions, time-dependent mass diffusion and mass generation characteristics. The first 6-hour leaching period would be enough to produce leaching data for determining the relevant parameters. The experimental time was much shorter than any other currently used test method for evaluating the diffusion behavior of a solidified waste matrix. The results from this designed leaching test can be used to simulate the behavior in actual field conditions.

The empirical mass diffusivity $\left(\alpha^{T}\right)$ and mass generation rate constant $\left(\mathrm{k}^{T}\right)$ were easily computed using least-squares method derived from Duhemel's diffusion values and ap- plied to simulate the amount of pollutants leaching from various cement-added matrices.

The mass diffusivity $\left(\alpha^{T}\right)$ and mass generation rate constant $\left(\mathrm{k}^{T}\right)$ vary with the amount of cement added to the waste matrix. This proved that this diffusion model could be used to simulate the released pollutant resulting from the addition of solidified agents.

Equation 22, which shows the diameter of the solidified waste matrix $(b)$ and its concentration $(C(r, t), C(t))$, infers that the amount of lead isotope that leached from the solidified waste matrix $g(t)$, and the leaching time $(t)$ were all related to the mass diffusivity $(\alpha)$.

An appropriate Bessel function root $\left(\beta_{m}\right)$ reflected the exact mass diffusivity value. From Equation 23, the mass diffusivity $(\alpha)$, leaching time $(\mathrm{t})$, concentration and diameter of the solidified waste matrix (b) are all related to the mass generation rate constant $(\mathrm{k})$. Thus, the mass diffusivity $(\alpha)$ and mass generation rate constant $(\mathrm{k})$, which were time-dependent parameters and a function of the cylinder diameter, were effectively demonstrated by this study.

The solidified waste cylinder leaching method and the corresponding 3-dimension mathematical diffusion model constitute a very useful and efficient alternative method

Table 4. Lead isotope leached from waste forms by experiment and empirical diffusion model.

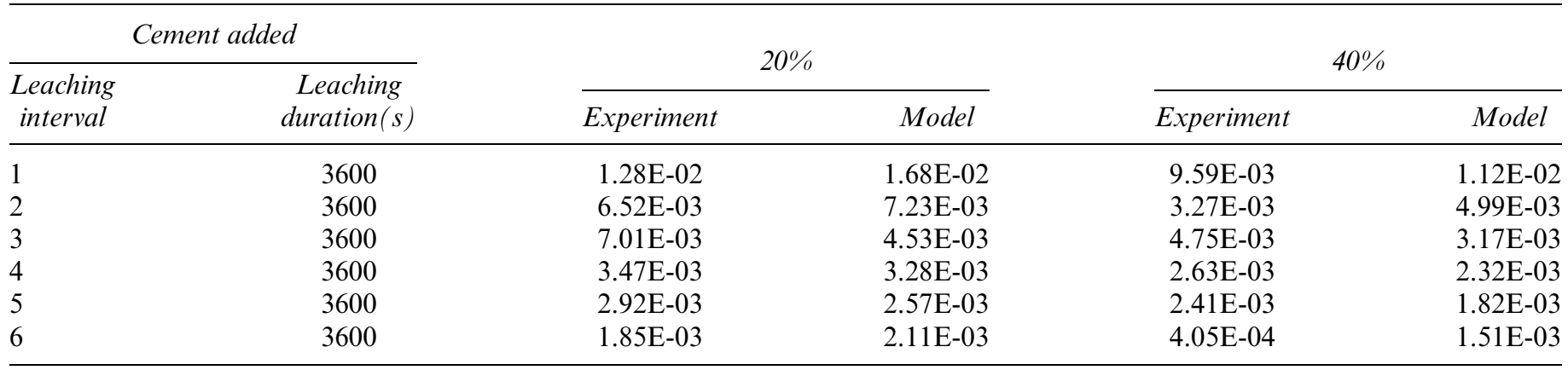




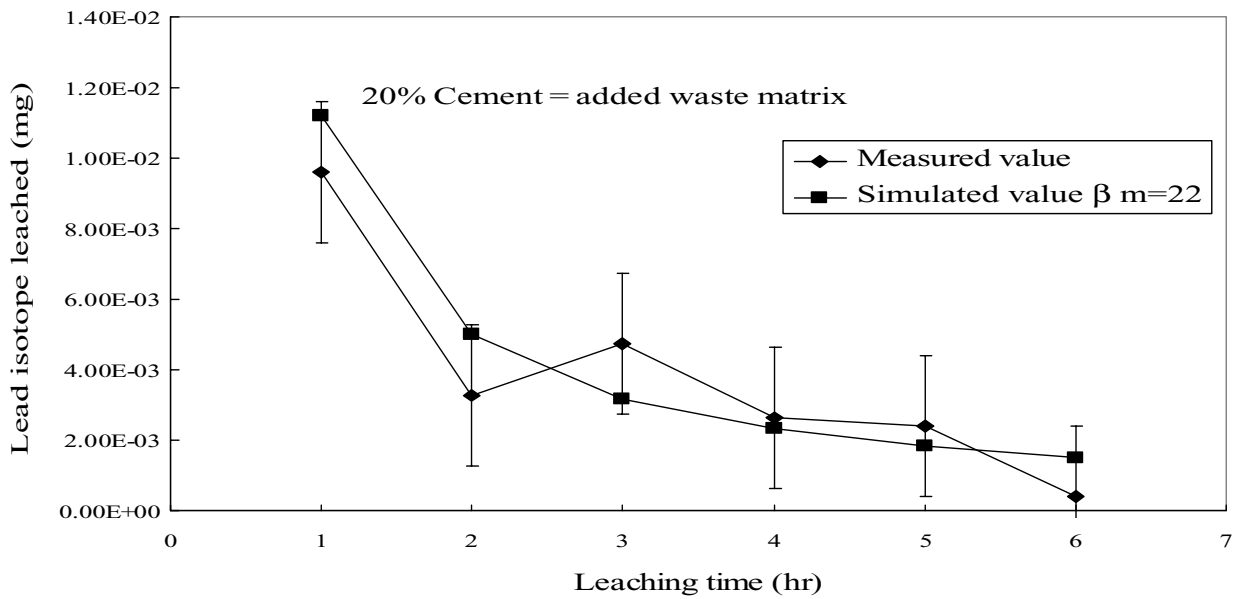

Fig. 3. A comparison of measured and simulated values of the lead isotope released from solidified waste matrix with $20 \%$ cement addition.

for evaluating waste solidification processes. From an administrative perspective, solidified waste matrix disposal requires that the solidified waste products be characterized and meet specified criteria for disposal permission to be granted. The three-dimension testing method coupled with a leaching behavior model for the solidified matrix developed in this study can be employed to forecast the amounts of contaminants leached. Furthermore, based on the mass generation rate of the contaminants leached out of the solidified waste matrix obtained from the diffusion model, the associated limit values leached from the solidified waste matrix could be scientifically established. From an engineering perspective, the solidified waste products could be utilized, e.g., as a filling material in an embankment. The material is generally placed on or below the ground surface above an aquifer. The diffusion model could be used to predict the maximum acceptable amount of a given component in the leachate through a sound waste solidification project. For such an engineering project, a cost-effective process can be thoroughly evaluated using the proposed model. From an environmental perspective, the role of risk assessment and risk management in environmental decision making have been accepted.

Thus, a relationship between the results from leached contaminants from a solidified waste matrix and the environmental risk posed by various engineering waste disposal methods should be performed. Using the proposed diffusion model, it is possible to estimate the incremental probability of some harm occurring. The three-dimensional leaching method for investigating the diffusion behavior developed in this study can be used as an effective tool for establishing the regulatory limits, designing disposal sites, and

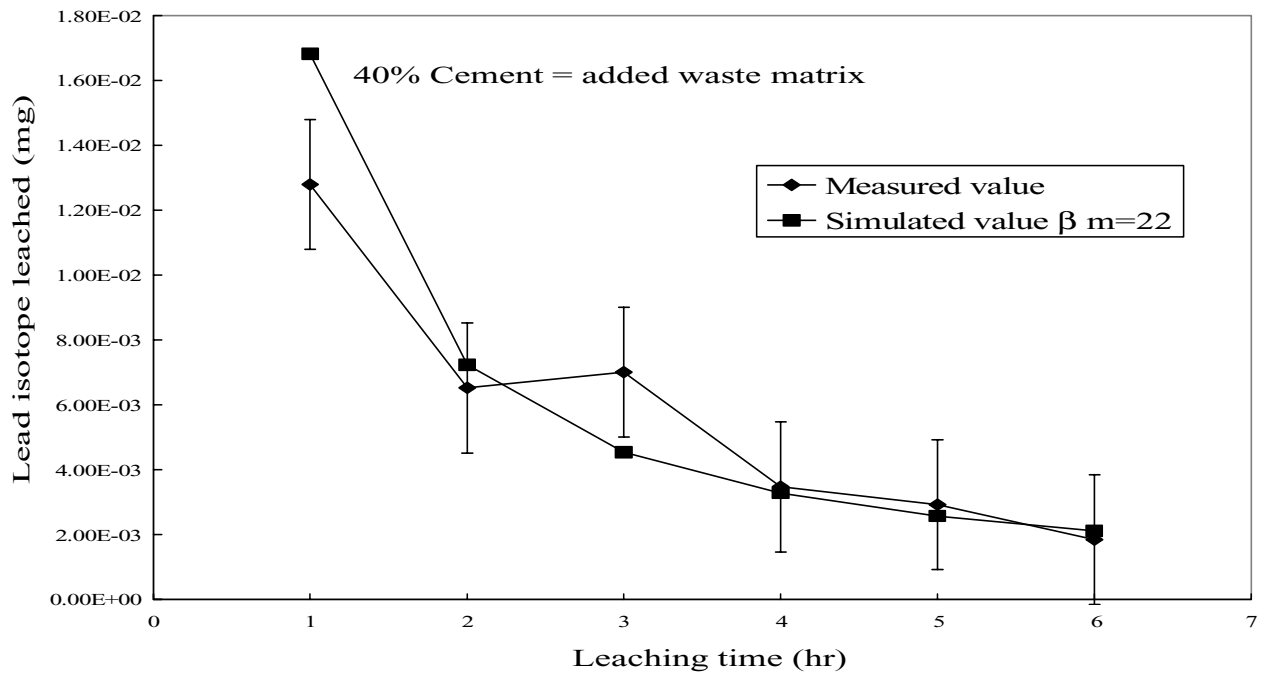

Fig. 4. A comparison of measured and simulated values of the lead isotope released from solidified waste matrix with $40 \%$ cement addition. 
performing risk assessment in the field of solidified waste management.

\section{Conclusion}

A three-dimensional diffusion model based on Duhamel's theorem was developed to simulate the diffusion behavior of a solidified waste matrix. An appropriate Bessel function root is the key to the diffusion model accuracy. A lead isotope release simulation was performed using the proposed diffusion model. The controlling parameters were derived from the experimental results using the leastsquares method. The diffusion model was calibrated and verified with extended leaching time from the simulated target pollutant leaching out of the waste cylinder. An appropriate Bessel function root demonstrated the exact diffusion model. The three-dimensional mass diffusion model showed good overall agreement between the simulation and experimental data through an experimental setup using a solidified waste matrix cylinder contained inside a cylindrical leaching vessel. The proposed model will also help reduce the time and expenses involved in investigating diffusion behaviour due to pollutant leaching from solidified waste matrices.

\section{Acknowledgment}

The authors wish to thank Institute of Nuclear Energy Research Atomic Energy Council, Executive Yuan, Taoyuan County, Taiwan for experimental support.

\section{References}

[1] Techobanoglous, G.; Schroeder, D. Primary drinking water standards. In Water Quality, Characteristics, Modeling, Modification. Addison-Wesley; Reading, MA, 1985, 721-724.

[2] Skelland, A.H.P. Molecular diffusivity. In Diffusional Mass Transfer, John Wiley \& Sons, Inc., New York, 1974; 49-77.

[3] Poon, C.S.; Chen, Z.Q.; Wai, O.W.H. The effect of flow-through leaching on the diffusivity of heavy metals in stabilized/solidified wastes. J. Hazard. Mater. 2001, B81, 179-192.

[4] Park, J.Y.; Batchelor, B. A multi-component numerical leach model coupled with a general chemical speciation code. Water Res. 2002, 36, 156-166.

[5] Baker, P.G.; Bishop, P.L. Prediction of metal leaching rates from solidified/stabilized wastes using the shrinking unreacted core leaching procedure. J. Hazard. Mater. 1997, 52, 311-333.

[6] Zill, D.G. Boundary value problems. In Differential Equations with Boundary-Value Problems, 2nd Ed.; PWS-KENT: Boston, MA, $1988 ; 527-574$.

[7] Ozisik, M.N. The use of Duhamel's. In Heat Conduction, 2nd Ed., John Wiley \& Sons, Inc., New York, 1993; 195-221.

[8] Jing, C.; Meng, X.; Korfiatis, G.P. Lead leachability in stabilized/solidified soil samples evaluated with different leaching tests. J. Hazard. Mater. 2004, B114, 101-110.

[9] Poon, C.S.; Chen, Z.Q. Comparison of the characteristics of flowthrough and flow-around leaching tests of solidified heavy metal wastes. Chemosphere. 1999, 38(3), 663-680.

[10] American Nuclear Society Standards committee working Group ANS-16.1, Measurement of the Leachability of Solidified Low-level Radioactive Wastes Using a Short-Term Test Procedure. American Nuclear Society, IL, 1986; 4-13.

[11] Godbee, H.W.; Joy, D.S. Assessment of the loss of radioactive isotopes from waste solid to the environment. Part I: background and theory, ORNL-TM-4333, Oak ridge national laboratory, Oak Ridge, TN, 1974.

[12] Herschel, W.; Godbee, H.W. Compere, E.L. A figure-of-merit determined from the ANS leachability Standard. Trans. Amer. Nucl. Soc. 1979, 33, 205-207. 


\section{Appendix A}

Intermediate steps in diffusion model development

\section{Part A}

Text Equation 8 and 10 are from the following Introduce text Equation 6 into text Equation 3

$$
\begin{aligned}
& \Phi(r, t)=1-\psi(r, t)=1-\frac{2}{b} \sum_{m=1}^{\infty} e^{-\alpha \beta_{m}^{2} t} \frac{J_{0}\left(\beta_{m} r\right)}{\beta_{m} J_{1}\left(\beta_{m} b\right)} \\
& C(r, t)=\int_{0}^{t} C(\tau) \frac{\partial \Phi(r, t-\tau)}{\partial t} d \tau(0 \leq r \leq b)
\end{aligned}
$$

Obtain the following equation

$C(r, t)=\int_{0}^{t} C(\tau) \frac{1-\frac{2}{b} \sum_{m=1}^{\infty} e^{-\alpha \beta_{m}^{2} t} \frac{J_{0}\left(\beta_{m} r\right)}{\beta_{m} J_{1}\left(\beta_{m} b\right)}}{\partial t} d \tau$
$C(r, t)=\int_{0}^{t} C(\tau) \frac{2 \alpha \beta_{m}^{2}}{b} \times \sum_{m=1}^{\infty} e^{\alpha \beta_{m}^{2} \tau} \frac{J_{0}\left(\beta_{m} r\right)}{\beta_{m} J_{1}\left(\beta_{m} b\right)} d \tau$
$C(r, t)=\frac{2 \alpha}{b} \sum_{m=1}^{\infty} e^{-\alpha \beta_{m}^{2} t} \beta_{m} \frac{J_{0}\left(\beta_{m} r\right)}{J_{1}\left(\beta_{m} b\right)} \int_{0}^{t} e^{\alpha \beta_{m}^{2} \tau} C(\tau) d \tau$

$\int_{0}^{t} e^{\alpha \beta_{m}^{2} \tau} C(\tau) d r \quad$ Integration by parts as follows

$\int_{0}^{t} e^{\alpha \beta_{m}^{2} \tau} C(\tau) d \tau=\left.\frac{1}{\alpha \beta_{m}^{2}} e^{\alpha \beta_{m}^{2} \tau} C(\tau)\right|_{0} ^{t}-\int_{0}^{t} \frac{1}{\alpha \beta_{m}^{2}} e^{\alpha \beta_{m}^{2} \tau} d C(\tau)$

$=\frac{1}{\alpha \beta_{m}^{2}} e^{\alpha \beta_{m}^{2} t} \times e^{-\alpha \beta_{m}^{2} t} \times\left. e^{\alpha \beta_{m}^{2} \tau} C(\tau)\right|_{0} ^{t}$

$-\int_{0}^{t} \frac{1}{\alpha \beta_{m}^{2}} e^{\alpha \beta_{m}^{2} t} \times e^{-\alpha \beta_{m}^{2} t} \times e^{\alpha \beta_{m}^{2} \tau} d(\tau)$

$=\frac{1}{\alpha \beta_{m}^{2}} e^{\alpha \beta_{m}^{2} t}\left[e^{-\alpha \beta_{m}^{2}(t-t)} C(t)-e^{-\alpha \beta_{m}^{2}(t-0)} C(0)\right.$

$\left.-\int_{0}^{t} e^{-\alpha \beta_{m}^{2}(t-\tau)} d(\tau)\right]$

$=\frac{1}{\alpha \beta_{m}^{2}} e^{\alpha \beta_{m}^{2} t}\left[C(t)-e^{-\alpha \beta_{m}^{2} t} C(0)-\int_{0}^{t} e^{-\alpha \beta_{m}^{2}(t-\tau)} d C(\tau)\right]$

Then

$$
\begin{aligned}
& C(r, t)=\frac{2}{b} \sum_{m=1}^{\infty} \frac{J_{0}\left(\beta_{m} r\right)}{\beta_{m} J_{1}\left(\beta_{m} b\right)} C(t)-\frac{2}{b} \sum_{m=1}^{\infty} \frac{J_{0}\left(\beta_{m} r\right)}{\beta_{m} J_{1}\left(\beta_{m} b\right)} \\
& \quad \times\left(e^{-\alpha \beta_{m}^{2} t} C(0)+\int_{0}^{t} e^{-\alpha \beta_{m}^{2}(t-\tau)} d C(\tau)\right)
\end{aligned}
$$

Let

$$
\frac{2}{b} \sum_{m=1}^{\infty} \frac{J_{0}\left(\beta_{m} r\right)}{\beta_{m} J_{1}\left(\beta_{m} b\right)}=1 \quad \text { and } \quad C(0)=0
$$

Then

$$
\begin{aligned}
C(r, t)= & C(t)-\frac{2}{b} \sum_{m=1}^{\infty} \frac{J_{0}\left(\beta_{m} r\right)}{\beta_{m} J_{1}\left(\beta_{m} b\right)} \\
& \times\left(e^{-\alpha \beta_{m}^{2} t} C(0)+\int_{0}^{t} e^{-\alpha \beta_{m}^{2}(t-\tau)} d C(\tau)\right)
\end{aligned}
$$

\section{Part B}

Text Equation 18 is from the following:

Three-dimensional homogeneous differential equation of mass diffusion in the cylindrical coordinate system,

$$
\frac{\partial C}{\partial r^{2}}+\frac{1}{r} \frac{\partial C}{\partial r}+\frac{1}{r^{2}} \frac{\partial^{2} C}{\partial \phi^{2}}+\frac{\partial C}{\partial z^{2}}=\frac{1}{\alpha} \frac{\partial C}{\partial t}
$$

where $C=(r, \phi, z, t)$. Assume a separation of variable in this form

$$
C(r, \phi, z, t)=\phi(r, \phi, t) \Gamma(t)
$$

Equation 1 becomes

$$
\frac{1}{\psi}\left(\frac{\partial \psi}{\partial r^{2}}+\frac{1}{r} \frac{\partial \psi}{\partial r}+\frac{1}{r^{2}} \frac{\partial^{2} \psi}{\partial \phi^{2}}+\frac{\partial \psi}{\partial z^{2}}\right)=\frac{1}{\alpha C(t)} \frac{d C(t)}{\partial t}=-\lambda^{2}
$$
as

The separation equations for $C(t)$ and $\psi$ are then taken

$$
\begin{aligned}
& \frac{d C(t)}{d t}+\alpha \lambda^{2} C(t)=0 \\
& \frac{\partial \psi}{\partial r^{2}}+\frac{1}{r} \frac{\partial \psi}{\partial r}+\frac{1}{r^{2}} \frac{\partial^{2} \psi}{\partial \phi^{2}}+\frac{\partial \psi}{\partial z^{2}}+\lambda^{2} \psi=0
\end{aligned}
$$

We assume a separation in this form

$$
\psi(r, \phi, z)=R(r) \Phi(\phi) Z(z)
$$

Equation 5 then becomes

$$
\frac{1}{R}\left(\frac{d^{2} R}{d r^{2}}+\frac{1}{r} \frac{d R}{d r}\right)+\frac{1}{r^{2}} \frac{1}{\Phi} \frac{d^{2} \Phi}{d \phi^{2}}+\frac{1}{Z} \frac{d^{2} Z}{d z^{2}}+\lambda^{2}=0
$$

The only way this equality is satisfied is if each group of functions is equated to an arbitrary separation constant in the form

$$
\begin{aligned}
& \frac{1}{Z} \frac{d^{2} Z}{d z^{2}}=-\eta^{2}, \frac{1}{\Phi} \frac{d^{2} \Phi}{d \phi^{2}}=-v^{2}, \quad \text { and } \\
& \frac{1}{R}\left(\frac{d^{2} R_{v}}{d r^{2}}+\frac{1}{r} \frac{d R_{v}}{d r}\right)-\frac{v^{2}}{r^{2}}=-\beta^{2}
\end{aligned}
$$

The separated equations and the elementary solutions become

$$
\begin{gathered}
\frac{1}{Z} \frac{d^{2} Z}{d z^{2}}+\eta^{2} Z=0 \quad Z(\eta, z): \sin \eta z \text { and } \cos \eta z \\
\frac{1}{\Phi} \frac{d^{2} \Phi}{d \phi^{2}}+v^{2} \Phi=0 \quad \Phi(v a): \sin v \phi \text { and } \cos v \phi(9 \mathrm{~b}) \\
\frac{d^{2} R_{v}}{d r^{2}}+\frac{1}{r} \frac{d R_{v}}{d r}+\left(\beta^{2}-\frac{v^{2}}{r^{2}}\right) R_{v}=0 \\
R_{v}(\beta, r): J_{v}(\beta r): Y_{v}(\beta r)
\end{gathered}
$$

The function $C(t)$ satisfies Equation 4, that is

$$
C(t): \varepsilon^{-\alpha \lambda^{2} t}
$$

where $\lambda^{2}=\beta^{2}+\eta^{2}$

Equation 9c is called Bessel's differential equation of order $\mathrm{v}$ and its solutions. $J_{v}(\beta r)$ and $Y_{v}(\beta r)$ are the 
Bessel functions of order v, of the first and second kind, respectively.

If concentration in the cylinder has no $\mathrm{z}$ dependence, Equation 1 becomes

$$
\begin{aligned}
& \frac{1}{\Phi} \frac{d^{2} \Phi}{d \phi^{2}}+v^{2} \Phi=0 \quad \Phi(v, \phi): \sin v \phi \text { and } \cos v \phi \text { (10a) } \\
& \frac{d^{2} R_{v}}{d r^{2}}+\frac{1}{r} \frac{d R_{v}}{d r}+\left(\beta^{2}-\frac{v^{2}}{r^{2}}\right) R_{v}=0 \\
& R_{v}(\beta, r): J_{v}(\beta r): Y_{v}(\beta r) \\
& \frac{d C(t)}{d t}+\alpha \lambda^{2} C(t)=0 \quad C(t): e^{-\alpha \lambda^{2} t}
\end{aligned}
$$

where

$$
\lambda^{2}=\beta^{2}
$$

Equation 10a is an eigenvalue problem. Its solution is $\beta=$ $\beta_{m}, \mathrm{~m}=1.2 .3 \ldots \ldots$ The corresponding solutions $X\left(\beta_{m}, x\right)$ are called the eigenfunctions of the problem.

The complete solution for the concentration $C(r, t)$ is constructed by linear superposition of the separated elementary solutions in the form

$$
C(r, t)=\sum_{m=1}^{\infty} c_{m} e^{-\alpha \beta_{m}^{2} t} R_{0}\left(\beta_{m}, r\right)
$$

The initial condition gives an equation in the diameter of $b$ cylinder as

$$
\mathrm{C}_{h}(r, t)=\sum_{m=1}^{\infty} C_{m} R_{0}\left(\beta_{m}, r\right) \quad \text { in } 0 \leq r \leq b
$$
erty:

The eigenfunction has the following orthogonality prop-

$$
\begin{aligned}
& \int_{0}^{b} r R_{v}\left(\beta_{m}, r\right) R_{v}\left(\beta_{n} r\right) d r=0 \quad \text { for } m \neq n \\
& \int_{0}^{b} r R_{v}\left(\beta_{m}, r\right) R_{v}\left(\beta_{n} r\right) d r=N\left(\beta_{m}\right) \quad \text { for } m=n
\end{aligned}
$$

where the normalization integral (or the norm), $N\left(\beta_{m}\right)$, is defined as

$$
N\left(\beta_{m}\right)=\int_{0}^{b}\left(R_{v}(\beta m, r)\right)^{2} d r
$$

To determine the $C_{m}$ we operate on both sides of Equation 12 by the operator $\int_{0}^{b} R_{v}\left(\beta_{m}, r\right) d r$ and utilize the orthogonality property given Equation 13 and find

$$
C_{m}=\frac{1}{N\left(\beta_{m}\right)} \int_{0}^{b} R_{v}\left(\beta_{m} r\right) F(r) d r
$$

The substitution of Equation 15 into Equation 12 yields the solution for the concentration as

$C_{h}(r, t)=\sum_{m=1}^{\infty} e^{-\alpha \beta_{m}^{2} t} \frac{1}{N\left(\beta_{m}\right)} R_{v}\left(\beta_{m} r\right) \int_{0}^{b} r^{\prime} R_{v}\left(\beta_{m} r^{\prime}\right) C_{h}\left(r^{\prime}\right) d r^{\prime}$
As boundary condition

$$
R_{v}=0, R_{v}\left(\beta_{m}, r\right)=J_{v}^{\prime}\left(\beta_{m} r\right)
$$

We can find the

$$
N\left(\beta_{m}\right)=\int_{0}^{b} r J_{v}^{2}\left(\beta_{m} r\right) d r=\frac{b^{2}}{2} J_{v}^{2}\left(\beta_{m} b\right)
$$

Let $v=0$ Equation 16 becomes

$$
\begin{aligned}
& C_{h}(r, t)=\frac{2}{b^{2}} \sum_{m=1}^{\infty} e^{-\alpha \beta_{m}^{2} t} \frac{J_{0}\left(\beta_{m} r\right)}{J_{1}^{2}\left(\beta_{m} b\right)} \int_{0}^{b} r^{\prime} J_{0}\left(\beta_{m} r^{\prime}\right) C_{h}\left(r^{\prime}\right) d r^{\prime} \\
& C_{h}(r, t)=\frac{2}{b^{2}} \sum_{m=1}^{\infty} e^{-\alpha \beta_{m}^{2} t} \frac{J_{0}\left(\beta_{m} r\right)}{J_{1}^{2}\left(\beta_{m} b\right)} \\
& \quad \times \int_{0}^{b} r^{\prime} J_{0}\left(\beta_{m} r^{\prime}\right)\left[C\left(r^{\prime}\right)-C_{s}\left(r^{\prime}\right)\right] d r^{\prime}
\end{aligned}
$$

\begin{tabular}{|c|c|c|c|c|c|}
\hline \multicolumn{2}{|c|}{$\begin{array}{c}\text { Cement } \\
\text { added }(\%)\end{array}$} & \multirow{2}{*}{\multicolumn{2}{|c|}{$\begin{array}{l}\text { Isotope lead } \\
\text { release ( } \mathrm{mg} \text { ) }\end{array}$}} & \multicolumn{2}{|c|}{$\begin{array}{c}\text { Isotope lead in } \\
\text { waste matrix ( } \mathrm{mg})\end{array}$} \\
\hline \multirow{2}{*}{$\begin{array}{l}\text { Leaching } \\
\text { interval }\end{array}$} & \multirow{2}{*}{$\begin{array}{c}\text { Leaching } \\
\text { duration(s) }\end{array}$} & & & 20 & 40 \\
\hline & & 20 & 40 & $1.05 E-01$ & $8.97 E-02$ \\
\hline 1 & 3600 & $1.28 \mathrm{E}-02$ & $9.59 \mathrm{E}-03$ & $9.17 \mathrm{E}-02$ & $8.01 \mathrm{E}-02$ \\
\hline 2 & 3600 & $6.52 \mathrm{E}-03$ & $3.27 \mathrm{E}-03$ & $8.52 \mathrm{E}-02$ & $7.69 \mathrm{E}-02$ \\
\hline 3 & 3600 & 7.01E-03 & $4.75 \mathrm{E}-03$ & $7.82 \mathrm{E}-02$ & $7.21 \mathrm{E}-02$ \\
\hline 4 & 3600 & $3.47 \mathrm{E}-03$ & $2.63 \mathrm{E}-03$ & $7.47 \mathrm{E}-02$ & $6.95 \mathrm{E}-02$ \\
\hline 5 & 3600 & $2.92 \mathrm{E}-03$ & $2.41 \mathrm{E}-03$ & $7.18 \mathrm{E}-02$ & $6.71 \mathrm{E}-02$ \\
\hline 6 & 3600 & $1.85 \mathrm{E}-03$ & $4.05 \mathrm{E}-04$ & $6.99 \mathrm{E}-02$ & $6.67 \mathrm{E}-02$ \\
\hline
\end{tabular}

\section{Appendix B}

A sample for empirical mass diffusivity, empirical mass generation rate constant and simulate isotope lead leached from solidified waste matrix

\section{Part A}

Empirical mass diffusivity calculated using the leastssquares method:

$$
\begin{aligned}
Y & =\frac{(C(r, t)-C(t)}{C(t)} * \frac{1}{\frac{2}{b} \sum_{m=1}^{\infty} \frac{\left.J_{0} \beta_{m} r\right)}{\beta_{m} J_{1}\left(\beta_{m} b\right)} \beta_{m}^{2}}=\alpha * t \\
Y 1 & =\frac{(1.05 E-01)-(9.17 E-02)}{9.17 E-02} * \frac{1}{\frac{2}{0.5} * 122}=2.86 E-04
\end{aligned}
$$

Cement

added (\%)

20

40

\begin{tabular}{lll}
\hline Y1 & $2.86 \mathrm{E}-04$ & $2.46 \mathrm{E}-04$ \\
Y2 & $1.57 \mathrm{E}-04$ & $8.72 \mathrm{E}-05$ \\
$\mathrm{Y3}$ & $1.84 \mathrm{E}-04$ & $1.35 \mathrm{E}-04$ \\
$\mathrm{Y} 4$ & $9.53 \mathrm{E}-05$ & $7.76 \mathrm{E}-05$ \\
$\alpha^{T}=\frac{[Y]}{[t]}$ & $5.02 \mathrm{E}-08$ & $3.79 \mathrm{E}-08$ \\
\hline
\end{tabular}

App. 1. Lead isotope leached from the waste matrix. 
Part B

Empirical mass generation rate constant calculated using the least-squares method

$$
\begin{aligned}
& Z=\left(\frac{[C(r, t)-C(t)]^{2}}{C(r, t) * C(t)} * \frac{1}{\sum_{m=1}^{\infty} \frac{J_{0}\left(\beta_{m} r\right)}{\beta_{m} J_{1}\left(\beta_{m} b\right)} \beta_{m}^{2}}\right) * \sum_{m=1}^{\infty} \frac{J_{0}\left(\beta_{m} r\right)}{\beta_{m} J_{1}\left(\beta_{m} b\right)}\left(1-e^{-\alpha \beta_{m}^{2} t}\right)=K * t \\
& \mathrm{Z} 1=\frac{[(1.05 E-01)-(9.17 E-02)]^{2}}{(1.05 E-01) *(9.17 E-02)} * \frac{1}{122} *(2.15 E-02)=(3.00 E-06)
\end{aligned}
$$

\begin{tabular}{lcr}
$\begin{array}{l}\text { Cement } \\
\text { added }(\%)\end{array}$ & 20 & 40 \\
\hline $\mathrm{Z} 1$ & $3.00 \mathrm{E}-06$ & $2.06 \mathrm{E}-06$ \\
$\mathrm{Z} 2$ & $1.87 \mathrm{E}-06$ & $5.47 \mathrm{E}-07$ \\
$\mathrm{Z} 3$ & $3.72 \mathrm{E}-06$ & $1.88 \mathrm{E}-06$ \\
$\mathrm{Z} 4$ & $1.36 \mathrm{E}-06$ & $8.34 \mathrm{E}-07$ \\
$\kappa^{T}=\frac{[Z]}{[t]}$ & $6.91 \mathrm{E}-10$ & $3.09 \mathrm{E}-10$ \\
\hline
\end{tabular}

Table 2. Roots of the Bessel function.

First 2 roots of Bessel function $J_{n}(\mathrm{z})=0 n=0,1$

$z=1 \quad b=0.5 \quad \beta_{m}=2$

$z=2 \quad b=0.5 \quad \beta_{m}=4 \quad$ and so on

\begin{tabular}{rrrrrrr}
\hline$z$ & $J_{0}\left(\beta_{m} r\right)$ & $J_{1}\left(\beta_{m} b\right)$ & $\beta_{m}$ & $\beta_{m}^{2}$ & $\frac{J_{0}\left(\beta_{m} r\right)}{J_{1}\left(\beta_{m} b\right) \beta_{m}} \frac{J_{0}\left(\beta_{m} r\right)}{J_{1}\left(\beta_{m} b\right) \beta_{m}} \times \beta_{m}^{2}$ \\
\hline 1 & 2.4048 & 3.8317 & 2 & 4 & $3.14 \mathrm{E}-01$ & $1.26 \mathrm{E}+00$ \\
2 & 5.5201 & 7.0156 & 4 & 16 & $1.97 \mathrm{E}-01$ & $3.15 \mathrm{E}+00$ \\
3 & 8.6537 & 10.1735 & 6 & 36 & $1.42 \mathrm{E}-01$ & $5.10 \mathrm{E}+00$ \\
4 & 11.7915 & 13.3237 & 8 & 64 & $1.11 \mathrm{E}-01$ & $7.08 \mathrm{E}+00$ \\
5 & 14.9309 & 16.4706 & 10 & 100 & $9.07 \mathrm{E}-02$ & $9.07 \mathrm{E}+00$ \\
6 & 18.0711 & 19.6159 & 12 & 144 & $6.61 \mathrm{E}-02$ & $1.11 \mathrm{E}+01$ \\
7 & 21.0711 & 22.7601 & 14 & 196 & $5.88 \mathrm{E}-02$ & $1.30 \mathrm{E}+01$ \\
8 & 24.3525 & 25.9037 & 16 & 256 & $5.26 \mathrm{E}-02$ & $1.50 \mathrm{E}+01$ \\
9 & 27.4935 & 29.0468 & 18 & 324 & $4.76 \mathrm{E}-02$ & $1.90 \mathrm{E}+01$ \\
10 & 30.6346 & 32.1897 & 20 & 400 & $4.35 \mathrm{E}-02$ & $2.10 \mathrm{E}+01$ \\
11 & 33.77582 & 35.33231 & 22 & 484 & $1.20 \mathrm{E}+00$ & $1.22 \mathrm{E}+02$ \\
& & & & Summation
\end{tabular}


For $\mathrm{Z} 1$ and $\beta_{1}=2$

$$
\sum_{m=1}^{\infty} \frac{J_{0}\left(\beta_{m} r\right)}{\beta_{m} J_{1}\left(\beta_{m} b\right)}\left(1-e^{-\alpha^{T} \beta_{m}^{2} t}\right)=(3.14 E-01)^{*}\left(1-e^{-(5.02 E-08) * 4 * 3600}\right)=(2.27 E-04)^{*}
$$

\begin{tabular}{lccccrr}
\hline & \multicolumn{5}{c}{$20 \%$ cement added waste form } \\
\cline { 2 - 6 }$t(\mathrm{sec})$ & 3600 & 7200 & 10800 & 14400 & 18000 & 21600 \\
\hline$\beta_{1}=2$ & $2.27 \mathrm{E}-04 *$ & $4.53 \mathrm{E}-04$ & $6.79 \mathrm{E}-04$ & $9.05 \mathrm{E}-04$ & $1.13 \mathrm{E}-03$ & $1.36 \mathrm{E}-03$ \\
$\beta_{2}=4$ & $5.68 \mathrm{E}-04$ & $1.13 \mathrm{E}-03$ & $1.70 \mathrm{E}-03$ & $2.26 \mathrm{E}-03$ & $2.82 \mathrm{E}-03$ & $3.38 \mathrm{E}-03$ \\
$\beta_{3}=6$ & $9.19 \mathrm{E}-04$ & $1.83 \mathrm{E}-03$ & $2.74 \mathrm{E}-03$ & $3.64 \mathrm{E}-03$ & $4.53 \mathrm{E}-03$ & $5.42 \mathrm{E}-03$ \\
$\beta_{4}=8$ & $1.27 \mathrm{E}-03$ & $2.53 \mathrm{E}-03$ & $3.77 \mathrm{E}-03$ & $5.00 \mathrm{E}-03$ & $6.21 \mathrm{E}-03$ & $7.41 \mathrm{E}-03$ \\
$\beta_{5}=10$ & $1.62 \mathrm{E}-03$ & $3.22 \mathrm{E}-03$ & $4.78 \mathrm{E}-03$ & $6.32 \mathrm{E}-03$ & $7.83 \mathrm{E}-03$ & $9.31 \mathrm{E}-03$ \\
$\beta_{6}=12$ & $1.97 \mathrm{E}-03$ & $3.89 \mathrm{E}-03$ & $5.76 \mathrm{E}-03$ & $7.58 \mathrm{E}-03$ & $9.36 \mathrm{E}-03$ & $1.11 \mathrm{E}-02$ \\
$\beta_{7}=14$ & $2.31 \mathrm{E}-03$ & $4.55 \mathrm{E}-03$ & $6.71 \mathrm{E}-03$ & $8.79 \mathrm{E}-03$ & $1.08 \mathrm{E}-02$ & $1.27 \mathrm{E}-02$ \\
$\beta_{8}=16$ & $2.65 \mathrm{E}-03$ & $5.19 \mathrm{E}-03$ & $7.61 \mathrm{E}-03$ & $9.92 \mathrm{E}-03$ & $1.21 \mathrm{E}-02$ & $1.42 \mathrm{E}-02$ \\
$\beta_{9}=18$ & $2.99 \mathrm{E}-03$ & $5.81 \mathrm{E}-03$ & $8.47 \mathrm{E}-03$ & $1.10 \mathrm{E}-02$ & $1.33 \mathrm{E}-02$ & $1.56 \mathrm{E}-02$ \\
$\beta_{10}=20$ & $3.32 \mathrm{E}-03$ & $6.40 \mathrm{E}-03$ & $9.27 \mathrm{E}-03$ & $1.19 \mathrm{E}-02$ & $1.44 \mathrm{E}-02$ & $1.67 \mathrm{E}-02$ \\
$\beta_{11}=22$ & $3.64 \mathrm{E}-03$ & $6.97 \mathrm{E}-03$ & $1.00 \mathrm{E}-02$ & $1.28 \mathrm{E}-02$ & $1.54 \mathrm{E}-02$ & $1.77 \mathrm{E}-02$ \\
sum & $2.15 \mathrm{E}-02$ & $4.20 \mathrm{E}-02$ & $6.15 \mathrm{E}-02$ & $8.01 \mathrm{E}-02$ & $9.80 \mathrm{E}-02$ & $1.15 \mathrm{E}-01$ \\
\hline
\end{tabular}

\begin{tabular}{lcccccr}
\hline & \multicolumn{5}{c}{$40 \%$ cement added waste form } \\
\cline { 2 - 6 }$t$ (sec $)$ & 3600 & 7200 & 10800 & 14400 & 18000 & 21600 \\
\hline$\beta_{1}=2$ & $1.71 \mathrm{E}-04$ & $3.42 \mathrm{E}-04$ & $5.13 \mathrm{E}-04$ & $6.84 \mathrm{E}-04$ & $8.55 \mathrm{E}-04$ & $1.03 \mathrm{E}-03$ \\
$\beta_{2}=4$ & $4.29 \mathrm{E}-04$ & $8.57 \mathrm{E}-04$ & $1.28 \mathrm{E}-03$ & $1.71 \mathrm{E}-03$ & $2.13 \mathrm{E}-03$ & $2.56 \mathrm{E}-03$ \\
$\beta_{3}=6$ & $6.94 \mathrm{E}-04$ & $1.39 \mathrm{E}-03$ & $2.07 \mathrm{E}-03$ & $2.76 \mathrm{E}-03$ & $3.44 \mathrm{E}-03$ & $4.12 \mathrm{E}-03$ \\
$\beta_{4}=8$ & $9.61 \mathrm{E}-04$ & $1.91 \mathrm{E}-03$ & $2.86 \mathrm{E}-03$ & $3.80 \mathrm{E}-03$ & $4.72 \mathrm{E}-03$ & $5.64 \mathrm{E}-03$ \\
$\beta_{5}=10$ & $1.23 \mathrm{E}-03$ & $2.44 \mathrm{E}-03$ & $3.63 \mathrm{E}-03$ & $4.81 \mathrm{E}-03$ & $5.98 \mathrm{E}-03$ & $7.12 \mathrm{E}-03$ \\
$\beta_{6}=12$ & $1.49 \mathrm{E}-03$ & $2.96 \mathrm{E}-03$ & $4.39 \mathrm{E}-03$ & $5.80 \mathrm{E}-03$ & $7.18 \mathrm{E}-03$ & $8.53 \mathrm{E}-03$ \\
$\beta_{7}=14$ & $1.76 \mathrm{E}-03$ & $3.47 \mathrm{E}-03$ & $5.13 \mathrm{E}-03$ & $6.75 \mathrm{E}-03$ & $8.33 \mathrm{E}-03$ & $9.86 \mathrm{E}-03$ \\
$\beta_{8}=16$ & $2.02 \mathrm{E}-03$ & $3.96 \mathrm{E}-03$ & $5.84 \mathrm{E}-03$ & $7.66 \mathrm{E}-03$ & $9.41 \mathrm{E}-03$ & $1.11 \mathrm{E}-02$ \\
$\beta_{9}=18$ & $2.27 \mathrm{E}-03$ & $4.45 \mathrm{E}-03$ & $6.53 \mathrm{E}-03$ & $8.52 \mathrm{E}-03$ & $1.04 \mathrm{E}-02$ & $1.22 \mathrm{E}-02$ \\
$\beta_{10}=20$ & $2.53 \mathrm{E}-03$ & $4.92 \mathrm{E}-03$ & $7.18 \mathrm{E}-03$ & $9.33 \mathrm{E}-03$ & $1.14 \mathrm{E}-02$ & $1.33 \mathrm{E}-02$ \\
$\beta_{11}=22$ & $2.78 \mathrm{E}-03$ & $5.37 \mathrm{E}-03$ & $7.81 \mathrm{E}-03$ & $1.01 \mathrm{E}-02$ & $1.22 \mathrm{E}-02$ & $1.42 \mathrm{E}-02$ \\
sum & $1.63 \mathrm{E}-02$ & $3.21 \mathrm{E}-02$ & $4.72 \mathrm{E}-02$ & $6.19 \mathrm{E}-02$ & $7.60 \mathrm{E}-02$ & $8.97 \mathrm{E}-02$ \\
\hline
\end{tabular}

\section{Part C}

The simulated lead isotope leached from waste matrix using the calibrated and verified diffusion model

$$
\begin{aligned}
G^{T}\left(t_{i}\right) & =\frac{k^{T} * b *\left(C(r, t)-\sum_{0}^{i} G^{T}\left(t_{i-1}\right)\right)}{2 * \alpha^{T} * \sum_{m=1}^{\infty} \frac{J_{0}\left(\beta_{m}^{r}\right)}{\beta_{m} J_{1}\left(\beta_{m} r\right)} \int_{\tau=0}^{t} e-\alpha T \beta_{m}^{2} t\left(1-\frac{\tau}{t}\right) d \tau} \\
G^{T}\left(t_{1}\right) & =\frac{(6.91 E-10) * 0.5 *(1.05 E-01)}{2 *(5.02 E-08) *(2.15 E-02)}=1.68 E-02 \\
G^{T}\left(t_{2}\right) & =\frac{(6.91 E-10) * 0.5 *((1.05 E-01)-(1.68 E-02))}{2 *(5.02 E-08) *(4.20 E-02)}=7.23 E-03
\end{aligned}
$$

